\title{
Da lingua partida: nomenclatura, coleção de vocábulos e glossários brasileiros
}

\author{
Language à part: nomenclature, collection of word marks \\ and Brazilian glossaries
}

Verli Petri Universidade Federal de Santa Maria, Santa Maria, RS, Brasil

Vanise Medeiros

Universidade Federal Fluminense, Niterói, RJ, Brasil

"Nem toda palavra é aquilo que o dicionário diz."

(O teatro mágico $)^{1}$

Resumo: Vocabulários e glossários, assim como os dicionários e gramáticas, constituem discursos sobre a língua, isto é, discursos que institucionalizam uma língua e que a trabalham como patrimônio. Neste artigo, propomos uma reflexão sobre a relação entre o regional e o nacional a partir de quatro obras: Colleção de vocábulos e frases usados na província de São Pedro do Rio Grande do Sul, de Pereira Coruja (1852), Popularium sulriograndense e o dialecto nacional, de Appolinario Porto Alegre (1870), e os glossários constitutivos das obras de $O$ dialeto caipira, de Amadeu Amaral (1920), e de O linguajar carioca, de Antenor Nascentes (1922).

Palavras-chave: Língua, regional e nacional. Vocabulários e glossários. Patrimônio. História das Ideias Linguísticas.

Abstract: Vocabularies and glossaries, as well as dictionaries and grammars, are discourses on a language, i.e., discourses that institutionalize a language and that work it as a patrimony. In this paper, we propose a reflection on the relationship between regional and national from four works: Colleção de vocábulos e frases usados na província de São Pedro do Rio Grande do Sul, by Pereira Coruja (1852), Popularium sulriograndense e o dialecto nacional, by Appolinario Porto Alegre (1870), and the glossaries from the works 0 dialeto caipira, by Amadeu Amaral (1920), and O linguajar carioca, by Antenor Nascentes (1922).

Keywords: Language, national and regional. Vocabulary. Glossaries. Heritage. History of Linguistic Ideas.

1 Esta epígrafe nos foi carinhosamente enviada por Lucília Romão. 


\section{Primeiras reflexões}

Que língua é essa que está institucionalizada nos instrumentos linguísticos? De imediato, a questão nos conduz a, pelo menos, duas reflexões: a primeira, no tocante à língua, a partir da qual diremos que se trata de uma língua "guardada" e que há guardiões sempre de plantão... A segunda tange aos instrumentos linguísticos, a partir dos quais entendemos

Verli que os sujeitos da e na língua têm acesso à língua imaginária sistema-

Petri tizada (passível de ensinar e de apreender), seja pela lista de palavras que um dicionário, um vocabulário ou um glossário pode "guardar", seja

Vanise Medeiros pelo número de regras que a gramática de uma língua comporta.

Aprendemos com Auroux (1992) que o funcionamento dos dicionários e das gramáticas é essencial ao processo de gramatização de uma língua. No espaço de constituição e institucionalização da língua portuguesa no e do Brasil não é diferente, pois esses instrumentos linguísticos ocupam um lugar de fundação e somam-se-lhes muitos outros; é disso, também, que vamos tratar no decorrer de nossa reflexão. A questão que se coloca agora engendra o processo de gramatização, ligando-o, mais diretamente, à institucionalização da língua trazida de Portugal, que, no entanto, não é a mesma, é outra: língua da e na ex-colônia que é o Brasil. Afinal, então, de que instrumentos linguísticos estamos tratando quando pensamos na institucionalização aqui da nossa língua nacional? Nosso recorte se faz sobre nomenclatura, coleção de vocábulos e glossários internos em livros de estudos dialetológicos. Diante desse material, algumas de nossas perguntas são: o que se guarda, por que e como se guarda?

Partindo do que propõe Auroux, estamos incluindo instrumentos linguísticos outros ${ }^{2}$, na tentativa de dar conta das relações entre o local, regional e nacional, em termos de língua no Brasil, em meados do século XIX e início do século XX. Em Petri (2012, p. 29), temos a afirmação de que

\footnotetext{
tratar de instrumentos linguísticos, hoje, é trazer à baila uma série de objetos que funcionam no interior do processo de instrumentação da língua, tais como: livros didáticos, dicionários de especialidades e ou de regionalismos, sites da internet, $\mathrm{Mu}-$ seu da Língua Portuguesa, diferentes materiais publicitários etc.
}

2 É necessário lembrar que Orlandi (2001) estende o escopo da gramatização para manuais, manifestações literárias, instituições de ensino, entre outros. Neste artigo, estamos incluindo, além de vocabulários, livros de dialetologia, como os de Amaral e Nascentes. 
De fato, nossas pesquisas têm nos levado a ampliar o rol de instrumentos linguísticos que trabalham a institucionalização da língua, dentre os quais destacamos, como exemplo, o jornal nos anos 50 (MEDEIROS, 2010), em que se tinha, na coluna do professor Bechara, um curso de língua portuguesa, à semelhança de uma gramática, publicado semanalmente em página fixa no Jornal do Brasil. Nesse caso, o jornal servia de suporte à gramatização da língua: dava-se a saber naquele espaço da gramática da língua pelo jornal. Caso diferente é o de 0 dialeto caipira, de Amadeu Amaral (um dos objetos deste artigo), que também já consideramos instrumento linguístico (MEDEIROS; MATTOS, 2012), na medida em que, com esse livro, delimita-se um certo falar indicado como dialeto caipira, isto é, nomeia-se uma porção de língua (local e regional) em solo brasileiro e dá-se a tal porção um Da língua partida contorno fonético, lexical e sintático, instaurando, assim, uma discursividade que vai ressoar até os dias atuais, tanto em manuais didáticos (MEDEIROS; MATTOS, 2012) quanto em livros sobre a linguagem, por exemplo, pois "Não há como negar que, em termos socioeconômicos São Paulo há muito superou o Rio de Janeiro, mas, por outro lado, mantém a sua marca localista, pelo menos na fala, a marca do chamado 'dialeto caipira"' (LEITE; CALLOU, 2002, p. 10).

Diante disso e pensando nas relações que se estabelecem na língua enquanto ela está em processo de institucionalização no final do século XIX e início do século XX, observamos uma forte partição sobre a língua, indicando o que seria local e regional. Tais partições podem funcionar, por um lado, como metonímias do nacional - na medida em que é posto como parte da língua; por outro lado, podem ser, contraditoriamente, excluídas do nacional por serem muitas vezes significadas como desvio, incorreção, vício, patologia, como ocorre em Amaral (MEDEIROS; MATTOS, 2012) e em Nascentes, como, por exemplo, "iremos ver os erros, tentar explicar a razão de ser deles, do mesmo modo que o médico estuda a etiologia das moléstias" (NASCENTES, 1953, p. 14), ou ainda "são do mais alto valor científico os casos de patologia linguística” (p. 12). É o que já apontamos em outros trabalhos como dentro-fora da língua (MEDEIROS, 2012) e que diremos ocorrer também em Amaral e Nascentes.

Cabe ainda acrescentar que nesse momento sócio-histórico, do final do século XIX (e para isto estamos tomando as obras de Coruja 
e de Apolinário3), observa-se também o empenho em trabalhar o que estamos apontando como partições na língua; agora, porém, indicando que suas origens não podem ser tributadas apenas ao saber instituído como lusitano ou hispano. A presença de outras origens, sobretudo a das línguas indígenas (que se fazem presentes nas quatro obras), emerge no discurso daqueles que estudam a língua e que tentam capturar

Verli

Petri

Vanise

Medeiros essa língua em listas de palavras.

É nessa relação tensa - que diz da origem, que diz das fronteiras e que confere um estatuto local ou regional ${ }^{4}$ - que emerge o sujeito. O sujeito na e da língua que é posta como una - dada pela oficialidade e nacionalidade que representa enquanto sujeito brasileiro. Se essa língua existe, ela é o que Orlandi (2001) denomina como "língua imaginária", regulada severamente pela gramática - que nos remete mais uma vez à ideia de que há um modo de guardar o "tesouro" intocado e intocável - e recenseada regularmente pelo dicionário, grande e pesado, que nos remete à ideia de que um livro poderia conter todas as palavras de uma língua; um "livro-cofre". Gramáticas e dicionários têm méritos inquestionáveis e um funcionamento necessário e imprescindível no processo de gramatização das línguas, mas, quando pensamos num sujeito na e da língua, já não podemos nos deter no que está posto na oficialidade que diz o que é nacional e o que não é, o que está certo e o que está errado... Afinal, estamos tratando do sujeito que fala e que cala, que ouve e finge não ouvir, disfarça, se distrai e se equivoca, que lê e que escreve, que entende e que não entende, que aceita e que resiste, enfim, do sujeito que produz sentidos e nas posições sujeitos postas nesses instrumentos nas quais os sujeitos se inscrevem. $\mathrm{O}$ sujeito tomado como heterogêneo pela própria partição na língua, dessa língua que é imaginária, mas cuja partição se dá num espaço de tensão, indicando sua fluidez. Isso significa dizer que não estão separadas por um estatuto (embora vocabulários, glossários e discursos sobre a língua engendrem fronteiras regionais), mas que há uma língua que não pode ser tomada como una.

3 Todas estas obras serão explicitadas mais adiante.

4 Há, como sabemos, outras partições e fronteiras, como as sociais. Aqui nossa preocupação reside nessa prática de mapeamento das línguas, presente no final do século XIX e atuante até meados do século XX, que tem como parâmetro a geografia, no caso, brasileira. A respeito dessa relação entre espaço e língua, há que se registrar que os estudos geográficos estavam intensamente ligados aos linguísticos há mais de dois séculos e que, na primeira metade do século XX, "todo manual de geografia possuía capítulos destinados à geografia linguística” (SOUZA, 1991, p. 11). 
Ao dizer isso, estamos tentando dar conta de um sujeito na e da língua que traz, em sua própria constituição histórica e social, a tensão entre o que é posto como língua imaginária nesses instrumentos e a língua fluida, a identificação com posições tomadas como próprias dos falares regionais, que se sustentam muitas vezes na literatura indicada e/ou sustentada como local ou regional ou mesmo em saberes considerados como populares ou folclóricos. Estamos pensando sobre as complexas relações entre o que é dado como nacional e o que é dado como regional. Em linhas gerais, outras das nossas questões são: como se dá a relação entre o nacional e o regional na língua? Que sujeito é este que se encontra na coleção de vocábulos e nos glossários?

Responder a tais questões, de uma perspectiva discursiva, não é tão simples, pois implica assumir o compromisso de questionar a eviDa língua partida dência, desconfiando de verdades tomadas historicamente como inquestionáveis; implica, sobretudo, aceitar o desconforto de não se ter respostas (tantas vezes desejadas). Como nos dizia Paul Henry (1993, p. 152), "se a questão é daquelas em que não se pode chegar ao fim, é possível deslocá-la, reformulá-la".

Nossa proposta, então, é de explicitar a tensão que permeia as relações entre língua e sujeito e como isso pode ser observado em vocabulários e glossários bem específicos, a saber (i) Colleção de vocábulos e frases usados na província de São Pedro do Rio Grande do Sul , de Pereira Coruja (ii) Popularium sulriograndense e o dialecto nacional, de Appolinario Porto Alegre; (iii) um glossário presente em 0 dialeto caipira, de Amadeu Amaral; e (iv) um glossário presente em O linguajar carioca, de Antenor Nascentes.

A nosso ver, isso faz deslocar a ideia de um "sujeito brasileiro" como universal para se pensar nas diferenças que dizem do sujeito que se inscreve nessa língua nacional que se parte. Partes de algo que não pode se encaixar. Em outras palavras, foi preciso partir para dizer do próprio, do que seria nacional, mas as partes - muitas, difusas, entrecortadas e entrelaçadas - não formam o todo; são partes que mantêm uma tensa

5 Assim era nomeado, à época, o estado do Rio Grande do Sul.

6 “A. A. P. Coruja publicou no Rio de Janeiro, em 1852, reeditada em 1856, em Londres, a 'Collecção de vocabulos e frases usados na provincia de São Pedro no Rio Grande do Sul', primeiramente saído na Revista do Instituto Historico e Geographico Brasileiro, tomo XV e, posteriormente, na Inglaterra, editada por Trübner \& Companhia. Sobre o vocabulário de Coruja houve ainda os 'Breves reparos de Ignacio José Malta', em Chorographia de Mello Moraes, v. II, p. 241-247. A edição de Trübner\& Cia., em Londres, em 1856, em volume de 32 páginas, in $8^{\circ}$, teve uma tiragem de 25 exemplares a expensas do príncipe L. L. Bonaparte. A edição do Rio, em 1861, foi impressa na Tipografia Moderna, de H. Gueffier, 64 páginas." (NEIVA, 1940, p. 8). 
relação com o nacional, numa tentativa, por vezes, de afirmação do local em detrimento de algo que vem de fora e que veio, sobretudo, do processo de colonização portuguesa; e, por vezes, numa tentativa de explicitar o que é regional, mas que é, sobretudo, constitutivo do que se entenderia como nacional, num Brasil em processo de afirmação de sua brasilidade.

É, pois, nessa relação entre nacional e regional que se instala tal Verli tensão, o que pode ser observado em instrumentos linguísticos que se rePetri lacionam com a gramática da língua, mas que fazem emergir, de fato, as diferenças quando se constituem como vocabulários e glossários locais e Vanise regionais. Por fim, tratar da língua e das tensões que nela e por ela se insMedeiros talam é também tratar da questão do sujeito. Nesse caso, o sujeito, tomado como brasileiro, diria respeito ao que tange à língua nacional, posta como oficial, e é quando introduzimos as discussões sobre o que é local e regional em relação ao nacional que estamos abrindo um espaço para pensar no sujeito heterogêneo, na tensão na língua. É preciso refletir sobre o lugar desse sujeito heterogêneo também quando se trata de dicionários de cunho nacional, pois ali emerge um processo de naturalização do lugar da diferença; há um modo de nomear a diferença, o que acontece com os regionalismos, que trazem a definição precedida da classificação "Reg." e que têm sua origem na língua em funcionamento nas diversas regiões que constituem o Estado-Nação, a qual, de algum modo, foi sistematizada em vocabulários e glossários elaborados como de uma ou de outra região.

\section{Nomenclatura, coleção de vocábulos e glossários regionais}

A nossa discussão neste artigo traz à baila a questão do sujeito nos modos de institucionalização da língua via instrumentos linguísticos, sobretudo no tocante a obras que se dizem locais e regionais, entre as quais, como já dito, destacamos especialmente a Colleção de vocábulos e frases usados na província de São Pedro do Rio Grande do Sul, de Pereira Coruja, publicado em 1852, na Revista do Instituto Histórico e Geográfico Brasileiro (com sede no Rio de Janeiro); o Popularium sulriograndense e o dialecto nacional, de Appolinario Porto Alegre, publicado em 1870; e os glossários constitutivos das obras de 0 dialeto caipira, de Amadeu Amaral, publicado em 1920, e 0 linguajar carioca, de Antenor Nascentes, de 1922.

Para esta reflexão, selecionamos, então, duas obras oriundas da segunda metade do século XIX (a Colleção de vocábulos e frases usados na província de São Pedro do Rio Grande do Sul e o Popularium sulriograndense e o dialecto nacional) e duas do início do século XX ( 0 dialeto caipira e 
O linguajar carioca). É importante destacar que todas essas obras foram retomadas no decorrer do século XX, com algumas especificidades que vamos explicitar, quando for o caso, no decorrer de nossa reflexão.

A Colleção de vocábulos está disponível no site do Instituto Histórico e Geográfico Brasileiro ${ }^{7}$ e foi retomada e discutida por Walter Spalding $^{8}$, na década de 40, na Revista Província de São Pedro ${ }^{9}$. Já o Popularium foi reorganizado e editado por Lothar Hessel ${ }^{10}$, na década de 80 do século XX, quando foi suprimida do título a parte do "dialeto nacional". Spalding (1947, p. 159) julga que a “'Coleção' foi o primeiro vocabulário regional gaúcho que se publicou e, por isso, seu grande mérito"; ele se propõe a "reeditá-la, agora, entregando sua divulgação à Província de São Pedro". O trabalho de Spalding é marcado pelas notas que produz sobre a Coleção de vocábulos proposta por Coruja quase cem anos antes. Isso vai lhe dar um caráter de reedição - e repetição -, mas, sobretudo, de atualização, pois a repetição do vocabulário proposto por Coruja introduz os acréscimos de Spalding. Então, é preciso pensar que esse repetir tem, pelo menos, dois funcionamentos: o primeiro é trazer, à luz do século XX, os estudos de Coruja; e o segundo, atualizar essa Coleção de vocábulos, reiterando sentidos e mobilizando outros, sempre identificado o trabalho empreendido por Coruja como um lugar de fundação. No gesto da repetição, a atualização e o deslocamento ${ }^{11}$.

Há diferentes versões para se pensar na história do Popularium, de Apolinário Porto Alegre, entre as quais nos detemos em duas delas: a primeira diz que a obra teria sido publicada no século XIX, conforme nos coloca Neiva (1940) ${ }^{12}$; a segunda, de Lothar Hessel (PORTO ALEGRE, 1980),

7 Disponível em: <http://www.ihgb.org.br/rihgb.php?s=p>. Acesso: $1^{\circ}$ mar. 2013.

8 Walter Spalding (1901-1976), escritor e historiador, atuou em diferentes temáticas das áreas humanas e sociais.

9 O acervo histórico do Laboratório Corpus (PPGL/UFSM) dispõe da coleção completa da Revista Província de São Pedro, editada na década de 40 do século XX.

10 Lothar Hessel (1915-2007), escritor e estudioso da história, da língua e do folclore do Rio Grande do Sul. 11 Ver também Scherer e Petri (2012).

12 "Ainda em 1870, Appolinario Porto Alegre escreveu o Popularium sulriograndense e o dialecto nacional. Porto Alegre, neste trabalho, hoje grande raridade bibliográfica, propôs a substituição do vocábulo folk-lore, expressão aparecida pela primeira vez em 1846, na revista inglesa Atheneum, e prestigiada e vulgarizada mais tarde por Max Müller, pela denominação de populário. Recentemente, em trabalho aparecido em 1936 de F. Rodrigues Valle, Elementos de folk-lore brasileiro, este autor propõe a substituição da expressão folk-lore pelo termo demopsicologia, já registrado por Gonçalves Vianna, lembrando ainda como melhor uma outra que Rodrigues Valle criou, demosofia. Teschauer, quando em 1928 registra o termo populário, acha que é o mesmo ou melhor que folk-lore e se refere ao seu emprego no Rio Grande do Sul. Esquece-se, porém, de citar que o criador de tal neologismo foi Appolinario Porto Alegre" (NEIVA, 1940, p. 10). 
reorganizador, que afirma, no prefaciamento do Popularium, que tal obra não teria sido publicada ou, se foi, tal publicação se perdeu, já que ninguém tem um único exemplar. 0 dissenso instala-se, então, no tocante à existência ou não da publicação do Popularium; no entanto, ambos os historiadores tiveram acesso aos manuscritos, não restando dúvidas de que a obra foi produzida por Apolinário Porto Alegre, na segunda metade do Verli século XIX. Observa-se que Spalding (1946), ao produzir notas para a ColePetri ção de vocábulos, de Coruja, utiliza-se do trabalho de Apolinário Porto Alegre, referenciando-o como "vocabulário inédito" já estudado por Augusto Vanise Daisson ${ }^{13}$. Spalding caracteriza Apolinário como "estudioso e conhecedor Medeiros profundo do guarani, gostava por isso de guaranizar tudo" (p. 163).

O dialeto caipira, de Amadeu Amaral, de 1920, e O linguajar carioca, de Antenor Nascentes, de 1922, ambos compostos de glossários, são apontados nos estudos de dialetologia como obras capitais do início do século (FERREIRA; CARDOSO, 1994, entre outros). Obras que se fazem em um momento em que se vinha produzindo, desde o final do século XIX, um debate deveras fecundo sobre o que seria o brasileiro (MEDEIROS, 2001) e que resulta na Semana de 22. No caso, são obras que dizem da língua do lugar do filólogo. $O$ dialeto caipira encontra-se digitalizado ${ }^{14}$. Já 0 linguajar carioca foi republicado em 1953 em edição "completamente refundida". Na realidade, alguns acréscimos foram feitos em algumas partes. Para este trabalho, estamos tomando a primeira edição (de 1922) e a segunda edição (esta apenas à guisa de citação de página). No que se refere à segunda edição, não houve mudanças nas partes privilegiadas neste artigo, a saber, o glossário, o capítulo "Léxico" e as observações que fecham o livro.

Os dicionários, os vocabulários, bem como os glossários são lugares de memória na língua - e isto, de diferentes maneiras, encontra-se no trabalho, já seminal, de Nunes (2006). Memória que não se faz sem desvãos, interditos, apagamentos e deslocamentos; memória tensa, tecida na e sobre a língua nos procedimentos tornados prática no fazer dicionarístico: seleção, indicação sobre a palavra - se substantivo, se brasileirismo, por exemplo -, definição e/ou explicação, exemplificação, remissão a outros verbetes e fontes indicadas. Uma língua que, nesses lugares, vai funcionando como evidente e como patrimônio de uma nação (ou de uma região). Não é diferente nos glossários; estes, como sa-

13 Foi aluno e orientando de Apolinário Porto Alegre.

14 Disponível em: <http://www.dominiopublico.gov.br/download/texto/bi000004.pdf>. Acesso em: 10 mar. 2012. 
bemos com Auroux (2008), advieram de listas de palavras e resultaram em dicionários. Se os glossários têm tal trajetória, isso não significa, contudo, que perderam espaço para os dicionários. Ao contrário, continuam sendo produzidos seja em livros de literatura ou não.

Em nossas pesquisas, temos observado que seu funcionamento por vezes difere do dicionário, quando se têm, por exemplo, somente palavras ladeadas por outras palavras; por vezes não, quando se têm verbetes seguidos de classificações, explicações, definições, sinonímias e exemplos. No entanto, um glossário, qualquer que seja, não tem o mesmo estatuto do dicionário: este se apresenta na sociedade como lugar de consulta da língua - monumento de um patrimônio - e, como tal, Da língua partida adentra espaços escolares e institucionais, espaços privados e públicos quaisquer. Já o glossário não se apresenta como tal; outro leitor aí se inscreve. Grosso modo, diremos que se destina a um público mais específico; mais restritos são os seus espaços de circulação. Se um dicionário produz o efeito de completude, diremos que no glossário o efeito é outro, o de parte especial e específica na língua, isto é, o glossário aponta para uma especificidade qualquer, seja de um texto literário, seja de uma região, por exemplo ${ }^{15}$.

Listas de palavras, como já dissemos, e vocabulários surgiram antes dos glossários. Estes advieram daqueles. Vocabulários e glossários, assim como os dicionários e as gramáticas, são discursos sobre a língua. São discursos que institucionalizam uma língua, que a trabalham como patrimônio; no nosso caso, que institucionalizam, por exemplo, um léxico como de um ou de outro lugar, revelando nuances de sentidos, diferenças e aproximações, compondo, juntos, a heterogeneidade constitutiva dessa língua. Esta breve reflexão sobre glossários, que se estende aos vocabulários, deve-se ao material aqui selecionado, a partir do qual pretendemos pensar a relação entre o nacional e o regional.

A primeira obra mencionada, de Pereira Coruja, não é nomeada como vocabulário ou dicionário, mas segue as regras básicas que fazem dela uma lista de palavras em ordem alfabética, com uma classificação gramatical mínima que explicita quando se trata de verbo (v.), de substantivo (s. m. ou s. f.) e de adjetivo (adj.); singular ou plural (pl.), particípio (partic.) etc., o que indica, como apontamos, um funcionamento

15 Ou ainda de uma classe social. 
próximo daquele que se tornou prática comum aos dicionários ${ }^{16}$. De fato, Coruja traz à luz uma lista de vocábulos e frases usados ao sul do Brasil (com suas relações de fronteira) e propõe-se a fazer "uma coleção com suas respectivas explicações, dando a muitos a origem provável, e deixando de outros a quem com mais critério os possa investigar" (1852, p. 208). Por tudo isso, tomaremos, neste trabalho, a obra de Coruja como

Verli um vocabulário regional, buscando estabelecer relações com os demais Petri instrumentos linguísticos em estudo.

Nesse caso, estamos trazendo à discussão um vocabulário, o de Vanise Pereira Coruja, que principia em meados do século XIX, e a sua reedição Medeiros comentada quase cem anos depois, por Walter Spalding, que, segundo Laytano (1981, p. 133), “transcreveu na íntegra a coleção do primeiro vocabulário gaúcho e depois, ao final de cada letra, escreveu novo verbete, inteiramente seu. Assim, há o vocabulário de Pereira Coruja e o vocabulário de Walter Spalding." Isso pode ser observado na publicação de Spalding, que, por sua vez, também consulta os manuscritos do Popularium, enquanto proposta de Nomenclatura Geral, de Apolinário Porto Alegre (1870), utilizando-se duplamente das pesquisas empreendidas no século XIX. É preciso explicitar essas relações, porque são constitutivas de sentidos e não meras coincidências; as nossas escolhas se dão a partir de objetivos bem específicos, e um deles é observar como se dá o processo de institucionalização da língua, considerando seus gestos fundantes, mas, sobretudo, as retomadas e os avanços que se produzem na e pela língua compilada nesses instrumentos linguísticos.

A segunda obra estudada é nomeada inicialmente como Popularium sulriograndense e o dialecto nacional, produzida por Apolinário Porto Alegre, e esse título traz em seu escopo elementos muito significativos. Dizer popularium, nesse momento histórico-social, significa entre outras coisas a reunião de fragmentos de resultados de pesquisa desenvolvida pelo autor, contemplando tanto os aspectos da linguagem (de uma perspectiva filológica) quanto os aspectos culturais (de uma perspectiva folclórica). Em outras palavras, dava-se a saber da língua e do estar na língua (enquanto sujeito). No popularium sulriograndense, temos indicado o que seriam as peculiaridades de uma região brasileira, de um estado da federação, de uma especificidade local. Isso é o que se mantém na publicação

16 Embora José Horta Nunes (2008), ao tratar do surgimento dos dicionários monolíngues no Brasil, classifique a obra de Pereira Coruja como um "dicionário parcial", optamos por tratá-lo aqui como "vocabulário", nomenclatura que atende melhor aos objetivos deste estudo. 
a que temos acesso para este estudo, pois a parte do dialecto nacional já não comparece na publicação do século XX. Esse corte ou recorte pode justificar-se nas necessárias escolhas que fizeram o reorganizador, Lothar Hessel, e o filho de Apolinário Porto Alegre, Álvaro, mas pode também justificar-se no fato de que a questão da língua nacional, nesse momento de publicação, já não está mais em voga. Em outras palavras, o que em meados do século XIX ainda provocava calorosos debates, encontra-se em 1980 já devidamente nomeada e institucionalizada. O que sustenta o trabalho de Apolinário é o diversificado conhecimento de línguas, pois, segundo Laytano (1981, p. 93), o autor do Popularium "estuda as línguas de índios, o tupi, o guarani, o azteca e as do negro como o banto, sudanês e quimbundo. [...] Entra no estudo do alemão. Diz-se que Apolinário lia o Rig-Veda em sânscrito".

Da língua partida

Feitas essas considerações sobre o Popularium e sobre seu autor, vamos tomar uma parte dele para estudo, a que foi intitulada, pelo próprio Apolinário Porto Alegre, como Nomenclatura geral, o que na reorganização de Lothar Hessel passa a ser um subtítulo da sessão que o reorganizador denominou como Vocabulário rio-grandense ${ }^{17}$. Por tudo isso, cabe a nós tomarmos esse Vocabulário para análise, mas não sem antes trazermos questões importantes: por que nomenclatura geral em meados do século XIX? Como seria pensar uma nomenclatura geral para alguém que está preocupado em compilar o vocabulário posto como próprio da sua região e, ao mesmo tempo, com um dialecto nacional... Temos, atualmente, uma nomenclatura gramatical brasileira, mas não uma nomenclatura geral que se preocupe em estabelecer regras gerais para a constituição de um vocabulário ou glossário ou dicionário. Certamente que disso se ocupam a lexicologia e a lexicografia, propondo tratamentos específicos para os verbetes, respeitando as especificidades temáticas, sociais etc. Pensar, no final do século XIX, em uma nomenclatura geral é o que também suscita em nós o trabalho de Apolinário Porto Alegre. Quais seriam as pretensões do autor de um popularium ao propor uma nomenclatura geral? As possíveis respostas a essa questão são temas de outro trabalho, mas aqui temos de destacar este gesto metalinguístico de Apolinário, gesto que o inscreve como autor brasileiro que diz da língua no Brasil e da necessidade de critérios para (a)preendê-la.

17 O Vocabulário rio-grandense subdivide-se em 1.1 Nomenclatura geral; 1.2 Locuções e expressões nativas. Formas idiotísticas; 1.3 Flora. Nomenclatura geral; e 1.4 Vocabulário da fauna rio-grandense. 
No que se refere às duas obras do século XX aqui consideradas, cabe dizer que seus títulos - $O$ dialeto caipira e $O$ linguajar carioca - já indicam outras partições na língua em solo brasileiro: uma que seria, conforme Amaral, do roceiro, do caipira inculto, daí dialeto caipira; outra, que seria da região carioca, com Nascentes. Uma posta como dialeto; outra como linguajar. Com a primeira, a divisão que a sustenta é entre o urbano Verli culto e o rural inculto (MEDEIROS; MATTOS, 2012), que se julga capturar Petri e dar contornos. É interessante que a divisão social - culto e inculto - que comparece no título - caipira - é proposta como de uma região e se faz Vanise significar como regional. Com o segundo, diremos que há uma compleMedeiros xidade maior na medida em que a divisão se dá a ver entre o culto posto como correto ("Pouco nos interessa a língua das classes cultas, primeiro porque é correta, segundo porque lhe falta a espontaneidade da língua popular" [NASCENTES, 1953, p. 14]) e o inculto, tal como no de Amaral, e de que forma tal é pensado como de uma região. Ambos indicam que são fortes, pois, nesse momento, as fronteiras geográficas se sobrepõem às sociais. No entanto, em Nascentes, a região é a metrópole e, com isso, a marca do inculto vai significar como "locuções populares" ou "gírias" (NASCENTES, 1922) de uma grande metrópole, ou seja, há aí um deslocamento que vai permitir a indicação da gíria, o que não ocorre em Amaral. Indo adiante, julgamos que o fato de o Rio ser capital vai impedir no título o termo "dialeto" - polêmica à época e presente na introdução de Nascentes - e a divisão na língua vai filiar-se a uma divisão entre escrita - portuguesa - e fala - brasileira, inscrita no título "linguajar carioca".

Colleção de vocábulos e frases usados na província de São Pedro do Rio Grande do Sul e Popularium sulriograndense e o dialecto nacional fazem parte do que Ferreira e Cardoso (1994) apontam como primeira fase dos estudos dialetais no Brasil. De acordo com as autoras, essa é uma fase caracterizada pelos trabalhos voltados para estudos lexicais e suas especificidades. Na lista das autoras consta o Popularium de Apolinário, entre outros produtos ${ }^{18}$. Ainda consoante às autoras, essa

18 Dicionário da língua brasileira, de Luís Maria Silva Pinto (1932); Vocabulário brasileiro para servir de complemento aos dicionários da língua portuguesa, de Brás da Costa Rubim (1953); Popularium sulriograndense e o dialeto nacional, de Apolinário Porto Alegre (1982); Estudos lexicográficos do dialeto brasileiro sobre algumas palavras africanas introduzidas no português que se fala no Brasil, de Antônio Joaquim Macedo Soares (1880, publicado na Revista Brasileira, tomo IV); O dialeto brasileiro, de Pacheco da Silva Junior (1880, publicado na Revista Brasileira, tomo IV); Glossários de vocábulos brasileiros, tanto derivados conhecidos como daqueles cuja origem é ignorada, de Visconde de Beaurepaire-Rohan (1883-1884, na Gazeta Literária, transformado no Dicionário de vocábulos brasileiro, 1889); Linguagem popular amazônica, de José Veríssimo (1994); Dicionário brasileiro da língua portuguesa, de Macedo Soares (1888); o tupi na geografia nacional, 
é uma fase que se inicia em 1826 e que termina em 1920, com a publicação de 0 dialeto caipira.

O dialeto caipira e 0 linguajar carioca compõem, conforme Ferreira e Cardoso (1994), a segunda fase dos estudos dialetais no Brasil, que se caracteriza pela "predominância de trabalhos voltados para os estudos gramaticais", embora, e isto interessa ressaltar, sejam "numerosos estudos de natureza lexicográfica" (FERREIRA; CARDOSO, 1994, p. 39). Esta segunda fase, para essas autoras, termina em 1952, quando se passa a ter estudos sistemáticos sobre a língua. Em suma, para elas, a Colleção de vocábulos e frases usados na província de São Pedro do Rio Grande do Sul e o Popularium sulriograndense e o dialecto nacional integram a primeira fase, ao passo que $O$ dialeto caipira e $O$ linguajar carioca inserem-se em outra fase; naquela se acentuam os estudos lexicográficos, nesta se faz notar Da língua partida uma preocupação com estudos gramaticais sobre a língua, embora se produzam vários léxicos e glossários regionais ${ }^{19}$. Ambas são marcadas por estudos não sistemáticos.

Antes de prosseguir, cabe uma observação: se essas fases foram marcadas por estudos não sistemáticos, não podemos deixar de observar que em Apolinário havia uma preocupação com a nomenclatura para os estudos lexicográficos, seja procurando separar palavras de locuções, seja tentando identificar do que seria possível determinar a origem etimológica e do que não seria. Certamente, ele ficou ainda à margem da criação de um método, tal como concebemos atualmente, mas também podemos dizer que estava entendendo a importância de se ter um método para esse tipo de estudo.

Outra divisão nos é dada por Guimarães (1996). De acordo com esse autor, a Colleção de vocábulos e frases usados na província de São Pedro do Rio Grande do Sul e o Popularium sulriograndense e o dialecto nacional se encontrariam numa primeira fase, isto é, uma fase que se caracteriza por uma ausência de estudos da língua feitos no Brasil. É interessante observar que os autores com que estamos trabalhando, apesar de se

de Theodoro Sampaio (1901); Glossário paraense, de Vicente Chermont de Miranda (1905); Apostilas ao dicionário de vocábulos brasileiros, de P. Carlos Teschauer (1912); Vocabulário popular, de P. H. Souza Pinto (1921); Dicionário de brasileirismos, de Rodolfo Garcia (1913); Apontamentos para um vocabulário de termos e frases populares e de vocábulos corrente no estado com acepções diferentes, de F. A. Pereira da Costa (1917, na Revista do Instituto Arqueológico e Geográfico de Pernambuco).

19 A lista que elas apresentam no tocante a léxico e glossários regionais é: Vocabulário gaúcho, de Roque Callage (1926); Vocabulário do Nordeste do Rio Grande do Sul - linguagem dos praieiros, de Dante de Laytano (1933); O vocabulário pernambucano, de Pereira da Costa (1937); e Vocabulário amazonense de Alfredo da Maia (1939) (FERREIRA; CARDOSO, 1994). 
situarem nessa fase, são brasileiros e já demonstram tal preocupação. Em Guimarães, bem como em Ferreira e Cardoso, as obras de Amaral e Nascentes estão inseridas também em uma segunda fase, mas que se inicia no final do século XIX, com a publicação de gramáticas por autores brasileiros e pela fundação da Academia Brasileira de Letras. Em outras palavras, o que marca a segunda fase em Guimarães é a produção de um

Verli dizer da língua do lugar do brasileiro (produção de gramáticas e espaço Petri institucional da Academia Brasileira de Letras).

Estas duas tipologias que trouxemos nos ajudam a refletir sobre

Vanise Medeiros as obras selecionadas. Melhor explicitando, em meados do século XIX, como é possível observar na obra de Pereira Coruja, há a preocupação em compilar palavras da língua e seus sentidos na região sul do Brasil. Embora não se marque explicitamente uma diferença com a língua de Portugal, há uma referenciação à matriz portuguesa. Em Pereira Coruja encontramos a distinção entre um sujeito que fala a língua na "região da campanha" e o que é admitido "no centro das povoações" e é no intuito de compilar vocábulos - e respectivos sentidos - não encontrados em dicionários disponíveis à época que ele propõe a sua Coleção de Vocábulos. Em suma, a preocupação com o local não se fazia sem um tributo à matriz portuguesa, ou seja, numa relação de adição à matriz lusitana.

No Popularium de Apolinário Porto Alegre, encontramos uma pesquisa preocupada com as questões concernentes à língua falada do e no Brasil, situada e em pleno funcionamento na região sul; ele busca a realização de um levantamento etimológico primoroso para o que se tinha à época, vinculando as origens da maioria das palavras, que ele explora, a línguas indígenas e/ou africanas, o que não ocorre com tanta frequência em Coruja. Para Apolinário, as palavras dessa língua falada não deviam somente tributo assim à Língua Portuguesa de Portugal, já que suas raízes eram muitas vezes da língua indígena, africana, mas também castelhana, entre outras. Isso nos levou a refletir sobre as noções de local, regional e nacional, acrescentando aqui as relações do sujeito dessa língua com Portugal. Podemos dizer que na obra de Apolinário o regional vem para compor uma unidade nacional, uma unidade capaz de dar conta da heterogeneidade da língua; enquanto que estamos propondo como local o que se contrapõe com o que vem de fora, ao mesmo tempo em que completaria a língua, dada como padrão, imposta pelo colonizador. Diferentemente de Coruja, pensar o regional na obra de Apolinário é também observar o funcionamento da metonímia en- 
quanto processo de produção de sentidos que explicita os regionalismos como parte do todo, configurado pelo nacional; exemplos disso em dois verbetes:

Anum - Dança e canto do povo rio-grandense.

Apinchar - Atirar o laço e, fig [uradamente] ${ }^{20}$, lançar um objeto qualquer de uma pessoa para outra. [...] O mesmo em Minas, São Paulo, Santa Catarina, em Cima da Serra, no Rio Grande. [...] Etim.: no guarani apyl, laço corrediço.

Como podemos notar, em Apolinário, há um próprio do sul (verDa língua partida bete anum), mas também o que ocorre no Rio Grande do Sul (verbete apinchar) é remetido a outros estados brasileiros, mostrando um movimento na língua de formação de uma nação.

No que tange às obras de Amadeu Amaral e Antenor Nascentes, estas são produzidas, por um lado, em um momento que se diz do nacional em oposição a Portugal (e aqui estamos recuperando, além de Guimarães, Orlandi [2002]), e isso significa que é preciso observar a diversidade interna para configurar o que vai ser o nacional; por outro lado, essa diversidade interna, que também vai sendo capturada em glossários e vocabulários regionalistas (FERREIRA; CARDOSO, 1994), é marcada como tal. É, pois, necessário apontar aquilo que é próprio no solo brasileiro para configurar o nacional, e o que é próprio vai sendo marcado nesses estudos lexicográficos como de uma ou outra região; regional, portanto. Reside aí uma contradição que diremos própria do binômio regional/nacional: diz-se o regional para configurar o nacional, mas marcar como regional não implica necessariamente ser nacional. Parte que fará pertencer ao todo - nacional -, mas como parte. Melhor explicando, palavras advindas dos glossários adentram os dicionários da língua, ou seja, há nesses instrumentos linguísticos marcação para regional, mas não para aquilo que é nacional, ou seja, o nacional funciona nos dicionários como forma não marcada. Não como parte, mas sob o efeito de totalidade.

Se tomamos esse segundo momento (GUIMARÃES, 1996) em que é preciso dizer do regional para compreender o que aqui ocorre e marcar a diferença diante de Portugal, não necessariamente o que é

20 Acréscimo do reorganizador, Lothar Hessel. 
regional funciona como metonímia do nacional, como vimos com Apolinário. Mas é o que observamos, por exemplo, em Amaral e Nascentes. Os verbetes que compõem os glossários dos dois autores do século XX são postos como de uma ou de outra região brasileira e, ao mesmo tempo, excluídos como tal (por serem significados como "patologia", como forma desviante da língua, entre outros termos que indicam o

Verli

Petri

Vanise

Medeiros sem lugar na língua posta como nacional).

Em suma, o que estamos destacando nesses materiais estudados é que eles compõem movimentos distintos na relação entre regional e nacional e que esses movimentos adentram os dicionários. Uma ressalva se faz necessária: se, hoje, com um razoável distanciamento, podemos observar a tradição dicionarística brasileira atrelada a uma prática corrente primeiro em Portugal, isso não significa dizer que os nossos instrumentos linguísticos são uma transposição dos portugueses, há uma configuração social diferenciada, um "processo histórico singular" (NUNES, 2008, p. 357).

\section{Das partições na língua}

\section{Século XIX: Pereira Coruja e Apolinário}

A partir do que foi exposto na sessão anterior, buscamos, neste momento, mostrar na materialidade dos verbetes as questões teóricas trabalhadas com recortes da Coleção de vocábulos, de Pereira Coruja, e a respectiva retomada feita por Walter Spalding. Isso se dá pela escolha dos primeiros vocábulos propostos por Pereira Coruja, já que temos 27 entradas (verbetes) iniciadas com a letra "A" ${ }^{21}$, das quais Spalding comenta 19, em suas notas produzidas nos anos 40 do século XX.

No Popularium, são mais de quarenta páginas do que é nomeado (pelo reorganizador) como "Vocabulário rio-grandense", seguido do título pensado por Apolinário, que foi Nomenclatura geral. Vamos nos deter, aqui também, em alguns verbetes que iniciam com a letra " $\mathrm{A}$ " (são vinte verbetes, no total). De fato, não há uma classificação gramatical, apenas sinalizações que explicitam ao leitor o interesse de Apolinário pela Etimologia das palavras (Etim.) ou a sinalização de um Diminutivo (Dim.), ou ainda a presença de Exemplo (Ex.:).

0 primeiro aspecto que nos chama a atenção diz respeito ao que, de alguma forma, aproxima as duas obras, já que ambas são pro-

21 Seguimos, assim, um critério já percorrido por Nunes (2006, p. 207), quando considera a letra "p" para suas análises. 
duzidas a partir da linguagem própria ao Rio Grande do Sul, na segunda metade do século XIX. Num segundo momento, vamos explicitar o que os coloca em patamares diferentes, embora sejam ambos tomados como vocabulários. Vejamos:

i) A escolha da maioria dos verbetes evidencia as relações do homem com a terra e com os animais (gado, cavalo etc.). Conforme se pode observar nos verbetes dos dois autores:

Acolherar, v. a. - unir animais em colhera. Diz-se mais própriamente dos cavalos. (Pereira Coruja).

Da língua

partida

Abagualado - tornado bagual, selvagem, indômito. (Apolinário).

ii) A presença do prefixo "a" marcando a possibilidade de estar em processo, indicando movimento pelo verbo tornar ou tornar-se, o que é frequente tanto em Pereira Coruja quanto em Apolinário, conforme demonstram os verbetes selecionados:

Amadrinhar, v. a. - acostumar os cavalos a persistirem junto de uma égua a que se dá o nome de "Égua-madrinha". o cavalo assim acostumado se diz amadrinhado. (Pereira Coruja).

Acablocar-se - tornar-se trigueiro, ter a cor vermelha escura, tomar hábitos de índio. (Apolinário).

iii) O interesse pela identificação da origem da palavra e sua etimologia, em Apolinário, como podemos ver no verbete que segue:

Abombar - perder o animal as forças pela ação solar ou longa estirada, podendo aliás continuar a viagem, apenas descanse ou refresque o tempo. Figurado. Ficar acabrunhado:

[“Ai, saudades, Ainda me lembro

De um dia que lá cantei!

De amores meio abombado

Este verso lhe botei."

(Poesia popular anônima - O Balão).]

É o afrontar do Norte (B. Rohan).

Etim.: de amombá, consumir, gastar, acabar. $0 \mathrm{~m}$ permutou pela análoga labial $b$, o que pertence ao próprio guarani. Ver regra de Anchieta na In- 
trodução. Todos têm errado nesta etimologia. B. Rohan, que a suspeitou, deixou-se arrastar pela Zorobabel Rodrigues. Basta dizer que dicionário nenhum espanhol dá tal acepção, para repelir semelhante origem.

Em contraposição com o que está posto em Pereira Coruja, que busca, com frequência, uma ligação da sua Coleção de vocábulos com ori-

Verli gens lusitanas ou mesmo hispanas, sem, no entanto, tecer maiores exPetri plicações, como podemos observar no verbete que segue:

Vanise

Medeiros

60

Aperos, s. m. pl. (do cast. "apêro", no português temos "apeiro") os preparos necessários para ensilhar um cavalo: diz-se estar o cavalo "bem aperado", quando está ricamente ornado para montar-se.

iv) Ocorre a referência explícita tanto ao regionalismo, como ocorre em Apolinário, quanto às relações com a língua portuguesa, como podemos observar em Pereira Coruja, colocando-os em posições diferentes em relação à língua. Vejamos os verbetes:

Anum - Dança e canto do povo rio-grandense.

Aperos - ver (i).

\section{Século XX: Amaral e Nascentes}

O glossário de Amaral compõe a maior parte do livro $O$ dialeto caipira; já o de Nascentes é bem mais restrito e encontra-se ao final. Para este artigo, trabalhamos com os verbetes da letra " $A$ " nos dois autores. São 138 verbetes em Amaral e 44 em Nascentes. O glossário de Amaral apresenta classificação gramatical e indicação de gênero; em seguida, tem-se sinonímia (há uma grande regularidade desse tipo de funcionamento) ou explicações; por fim, exemplificações ${ }^{22}$. Em Nascentes, não há classificação gramatical, o movimento é, sobretudo, da sinonímia; poucas são as explicações e raros os exemplos. São, pois, dois funcionamentos distintos, como já apontamos inicialmente (um que se aproxima daquele do dicionário; outro que diríamos se apresentar como uma lista de palavras seguidas por outras). Observem-se os exemplos:

22 O glossário de Amaral apresenta também abonações aos verbetes. Tais abonações são interessantes na medida em que a língua posta como do roceiro é contraditoriamente caucionada pela literatura portuguesa, como Camões, por exemplo. 
Angú, s.m. - papas de farinha ou de fubá. Fig.: negócio desordenado, teia de intrigas e mexericos, coisa confusa, e ininteligível. (Amaral).

Angu - barulho, intriga, confusão (Nascentes).

Aparêio, aparelho, s.m. - Na loc. "aparêio de fumo", que compreende o isqueiro, a pedra, o fuzil, e parece que também é necessário para fazer o cigarro. (Amaral).

Aparelho, Apareio - telefone, pessoa que atua como médium. (Nascentes).

Em ambos, diferentemente do que se observou em Coruja e Apolinário, a captura da palavra é marcada por uma ortografia que flutua, Da língua partida como é o caso da acentuação nesses exemplos dados (angú, angu; aparêio, apareio). É marca da oralidade da língua que se apreende como sendo das regiões focalizadas; flutuação que se faz presente na inscrição do verbete, indicando a preocupação com a pronúncia, avisam eles; tensão, nós diremos, na língua posta como do outro: do "roceiro caipira", caso de Amaral, e do "léxico carioca", caso de Nascentes. É também movimento do que seria regional para nacional (aparêio, aparelho), em Amaral; movimento do nacional para o regional (aparelho, apareio), em Nascentes.

Se alguns verbetes são os mesmos, como pudemos ler anteriormente, os sentidos deslizam (caso de angú/angu) ou são outros (caso de aparêio/apareio). Nascentes já havia denunciado tal possibilidade no capítulo denominado "Léxico": "Com efeito, capital e mais importante cidade do Brasil, o Rio de Janeiro exerce sobre o resto do país uma força centrípeta que acarreta para o vocabulário carioca termos oriundos de todos os Estados" (NASCENTES, 1953, p. 181).

O próprio autor já havia apontado ainda a "força contrária", que consiste na repercussão dos neologismos cariocas para todo o país, dado o fato de o Rio ser capital. Esse autor destaca também a dificuldade de seguir o léxico desde seu nascedouro, ou seja, de se poder indicar de onde provêm alguns vocábulos. Ora, para além dessas dificuldades, o que nos interessa aqui destacar são os fenômenos de pronúncia que se marcam na grafia de alguns verbetes em Amaral e Nascentes:

Abancá(r); abridera; amarelá, marelá; aparêio, aparelho. (Amaral).

Abafar, abafá; alavanca, lavanca; arrumadeira, arrumadera; aparelho, apareio. (Nascentes). 
São, pois, ocorrências linguísticas comuns aos dois glossários, a saber:

v) supressão do fonema "r" final (caso de "abancá", em Amaral; e de “abafá”, em Nascentes);

vi) supressão de fonema no início de palavra (caso de "marelá", em Amaral; e de "lavanca", em Nascentes);

Verli

Petri

Vanise

Medeiros

vii) redução do grupo "ei" a "e" quando diante de "r", por exemplo (caso de "abridera", em ambos);

viii) "lh" vocaliza-se em "i" (caso de "aparêio"/"apareio").

Se tais ocorrências ${ }^{23}$ particularizam o "dialeto caipira", por que se fazem presentes no "linguajar carioca"? Se, por outro lado, são ocorrências nacionais, nas referidas obras são indicadas como regionais. Ademais, a grafia as denuncia como não nacionais...

O que é próprio, então, do regional? É esta uma das tensões de que falamos anteriormente ao indicarmos como sendo de uma região aquilo que comparece também em outra. É o que acontece com os verbetes. São muitos os verbetes comuns entre Amaral e Nascentes, são vários entre Coruja e Apolinário, mas também são significativos os comuns entre Coruja, Apolinário e Amaral, como "abombar", por exemplo, já visto em Apolinário, anteriormente, que comparece em:

Abombar, v. n. diz-se que o Cavallo. Quando tendo feito grande viagem em dia de calor, fica em estado de não poder mais caminhar; mas depois de refrescar ainda pôde continuar a viagem. (Pereira Coruja).

Abombá(r), v.i. - extenuar-se (o animal). (Amaral).

E ainda entre Apolinário, Amaral e Nascentes. Por exemplo:

Azular: Desaparecer, fugindo com pressa. Correr precipitadamente, escapar-se furtivamente. Etim.: de ayorá, no guarani. Traz Montoya: "Soltar o atado: ayorá. Soltar-se ele: oyerá." Vem dum sentido translato, isto é, fugir com a rapidez com que foge o preso que foi solto ou soltou-se. (Apolinário Porto Alegre).

23 Não é o caso, neste artigo, de procedermos a um estudo exaustivo dos dois glossários. Nosso objetivo, como dissemos, é problematizar aquilo que é posto como de uma região e ocorre em outra região, o que aponta para uma tensão no gesto de captura da língua que seria do outro. 
Azulá(r), v.i. - fugir, Sentido irônico ou burlesco. "O tal sojeito, quando eu fui atrais dêle, já tinha azulado" (Amaral).

Azular, azulá(r) - fugir. (Nascentes).

Neles, vemos o gesto de captura de um dizer que se julga próprio de um lugar, mas que os vocabulários e glossários, ao apreendê-los, denunciam sua movência por terras outras...

\section{Palavras finas: abombar, abombado: nacional ou regional?} Coruja, Apolinário, Amaral e Nascentes: quatro autores que trabalham Da língua uma língua partida, uma língua que se parte. Indo adiante, partições partida que tensionam, como dissemos, o todo de diferentes maneiras: na ilusão de compor o nacional como sua metonímia, como é o caso de Apolinário; na contradição com o nacional, como é o caso em Amaral e Nascentes. Já em Coruja, a partição se faz do lugar do gesto pioneiro que tenta capturar aquilo que não está ainda em nenhum lugar institucional, não está registrado em lugar algum à época, e que trabalha, assim, o acréscimo à língua do colonizador. Iniciamos nosso artigo com uma inquietação sobre o processo de institucionalização da língua e o que se guarda nos instrumentos linguísticos e, nesse momento, após as análises realizadas, podemos dizer que nos vocabulários e glossários, produzidos entre os séculos XIX e XX, guarda-se o desejo do sujeito que luta pela sua língua, pela institucionalização da língua falada em diferentes regiões do Brasil, muito embora o que é possível guardar é parte da língua, ainda que na ilusão de um todo nacional.

\section{Referências}

AUROUX, S. Listas de palavras, dicionários e enciclopédias: o que nos ensinam os enciclopedistas sobre a natureza dos instrumentos lingüísticos. Língua e Instrumentos Linguísticos, Campinas: Pontes, n. 20, p. 9-19, 2008.

A revolução tecnológica da gramatização. Campinas: Ed. da Unicamp, 1992. 
AMARAL, A. 0 dialeto caipira. Disponível em: <http://www.dominiopublico.gov.br/download/texto/bi000004.pdf>. Acesso em: 10 mar. 2012.

CARMO, L. A voz do caipira em Amadeu Amaral. In: LIMA, I. S.; CARMO, L. (Org.). História social da língua nacional. Rio de Janeiro: Editora da Casa de Rui Barbosa, 2008. p. 375-390.

Verli

Petri FERREIRA, C.; CARDOSO, S. A dialetologia no Brasil. São Paulo: Contexto, 1994.

Vanise Medeiros

LAYTANO, D. de. o linguajar do gaúcho brasileiro. Porto Alegre: Escola Superior de Teologia São Lourenço de Brindes, 1981.

LEITE, Y.; CALLOU, D. Como falam os brasileiros. Rio de Janeiro: J. Zahar, 2002.

GUIMARÃES, E. Sinopse dos estudos do português no Brasil: a gramatização brasileira. In: GUIMARÃES, E.; ORLANDI, E. (Org.). Língua e cidadania: o português do Brasil. Campinas: Pontes, 1996. p. 127-138.

HENRY, P. Sentido, sujeito e origem. Tradução de Eni P. Orlandi. In: ORLANDI, E. P. (Org.) Discurso fundador. Campinas, SP: Pontes, 1993. p. 151-162.

MEDEIROS, V. Um glossário contemporâneo: a língua merece que se lute por ela. Revista Rua, n. 18, 2012. Disponível em: <http:// www.labeurb.unicamp.br/rua/pages/home/capaArtigo.rua?id=132>. Acesso em: 28 fev. 2013.

Sabendo (d)a língua pelo jornal: o que colunas, publicações e produção de material nos dizem da língua. In: MEDEIROS, V.; TEDESCO, M. T. Travessia nos estudos de língua portuguesa: homenagem a Evanildo Bechara e Olmar Guterres. Rio de Janeiro: Dialogarts, 2010. p. 287-296.

- A constituição de um discurso fundador: o prefácio de Casa Grande \& Senzala. Revista Rua, n. 7, p. 107-126, 2001. 
MEDEIROS, V.; MATTOS, T. o dialeto caipira, de Amadeu Amaral: discurso fundador e acontecimento discursivo. Revista Confluências (2012), ed. 42. Dispinível em: <http://llp.bibliopolis.info/ confluencia/>. Acesso em: 28 fev. 2013.

NASCENTES. A. O linguajar carioca. Rio de Janeiro: Organização Simões, 1953.

. O linguajar carioca. Rio de Janeiro: Süssekind de Mendonça, 1922.

NEIVA, Arthur. Estudos da língua nacional. São Paulo: Companhia Editora Nacional, 1940.

NUNES, J. H. Dicionário, sociedade e língua nacional: o surgimento dos dicionários monolíngües no Brasil. In: LIMA, I. S.; DO CARMO, L. (Org.). História social da língua nacional. Rio de Janeiro: Edições Casa de Rui Barbosa, 2008. p. 353-374.

Dicionários no Brasil. Campinas: Pontes; São Paulo: Fapesp; São José do Rio Preto: Faperp, 2006.

Léxico e Língua Nacional: apontamentos sobre a História da Lexicografia no Brasil. In: ORLANDI, E. (Org.). História das Ideias Linguísticas: construção do saber metalinguísticos e constituição da língua nacional. Campinas, SP: Pontes, 2001. p. 71-88.

ORLANDI, E. Língua e conhecimento lingüístico. Campinas: Cortez, 2002.

Apresentação. In: ORLANDI, E. (Org.). História das ideias linguísticas: construção do saber metalinguístico e constituição da língua nacional. Campinas: Pontes, 2001. p. 7-20.

Sentido, sujeito e origem. Trad. Eni Puccinelli Orlandi. In: ORLANDI, E. P. (Org.) Discurso fundador. Campinas, SP: Pontes, 1993. p. 151-162. 
PEREIRA CORUJA, A. A. Collecção de vocábulos e frases usados na província de São Pedro no Rio Grande do Sul. Disponível em: <http://www.ihgb.org.br/rihgb.php?s=p>. Acesso em: 1ํmar. 2013.

PETRI, V. Gramatização das línguas e instrumentos linguísticos: a especificidade do dicionário regionalista. Língua e instrumentos Verli linguísticos, Campinas: RG Editora, n. 29, p. 23-37, jan./jun. 2012.

Petri

Vanise Um outro olhar sobre o dicionário: a produção de sentidos. Medeiros

PORTO ALEGRE, A. Popularium sul-rio-grandense. 2. ed. Reorganização de Lothar Hessel. Porto Alegre: Ed. da UFRGS, 1980.

SPALDING, W. Coleção de vocábulos e frases usados na província de S. Pedro do R. G. do Sul - Antonio Alvares Pereira Coruja - Anotações de Walter Spalding. In: Província de São Pedro. Porto Alegre: Globo, 1947. p. 159-165.

SCHERER, A. E.; PETRI, V. Os homens que compraram madrugadas... Pereira Coruja e Walter Spalding na história do falar gaúcho. In: MASSMANN, D.; CINTRA, G. Linguagem e historicidade. Campinas: RG Editora, 2012.p. 59-76

SOUZA, Á. J. Geografia linguística. São Paulo: Contexto, 1991. 